Session 1566

\title{
Developing an Industry Sponsored Capstone Learning Environment
}

\author{
Harold A. Evensen, Paula F. Zenner, Thomas R. Grimm, Martin D. Tervo \\ Michigan Technological University
}

\begin{abstract}
A capstone learning experience that educates over two hundred mechanical engineering seniors annually has been developed in the Department of Mechanical Engineering-Engineering Mechanics at Michigan Technological University. The two-course sequence program draws on the traditional academic elements of mechanical engineering while incorporating real industrial problem solving, corporate environments, concept validation and prototyping in a teamed setting. Over seventy-five percent of the projects are sponsored by industry. Delivery structure, implementation barriers, funding models, evaluation and assessment methods will be presented.
\end{abstract}

Introduction

The Department of Mechanical Engineering-Engineering Mechanics at Michigan Technological University did a thorough study of ABET design requirements under the new guidelines. An initial review and benchmarking of universities also indicated that industrial sponsorship of a large percentage of projects would be educationally important and that a full academic year (two semesters) of senior design would be necessary to complete challenging projects. The initial concerns of the department were facilities requirements, providing a sufficient number of faculty advisors and the difficulty scheduling the anticipated 250 mechanical engineering seniors per year. The current system was phased in over a two year period with a requirement of a full semester of senior design for senior students "caught' in the transition. The requirement under the previously used quarter system was just one quarter of senior design. Industry sponsorship started very small, at about twenty-five percent of all projects and has grown to more that seventy-five percent.

Michigan Tech supports one of the largest mechanical engineering programs in the country. The large number of students in the senior design sequence has made it necessary to focus on logistics and delivery methods. Team size has remained small (3-6 students per team) while the lecture portion has been optimized for large enrollments. Facilities in the 13-story mechanical engineering building were expanded during the summer of 2000, just prior to the semester conversion. Space in the ME-EM building was converted from offices and labs to student design studios, prototyping and fabrication labs. There was also an expansion of the machine shop to enable completion of design projects from concept to prototype construction and testing. 


\section{Background and Benchmarking}

The design requirements for mechanical students at Michigan Technological University have undergone numerous changes over the past thirty or so years. Based on interpretations of ABET requirements and trends in engineering education students in the seventies were allowed to select from different "options" in mechanical engineering. One of these options was a specialization in design, which required that students complete a sequence of up to three quarters, or 9-credits, of design project courses. Later on in the eighties students were able to meet their "design requirement" by completing a certain number of "D" designated courses which had a significant design component built in via virtue of project assignments and class content. The design majors were still required to take at least the first course of the senior design project sequence, with most of these students completing at least two three credit senior design project courses. In the nineties all mechanical engineering students were required to complete one quarter of senior design. Most of the projects during this time period were defined by the senior design course coordinator/instructor based on input from both faculty and contacts in industry. The projects included the SAE sponsored vehicular design projects as well as projects sponsored by ASME and other professional engineering organizations. A small number of the design projects were supported by industry with a moderate amount of financial support as well as input from professionals at the sponsoring companies.

In the late nineties a decision was made by the Michigan Tech Administration to convert from quarters to semesters beginning in the fall of 2000. Prior to making the change from quarters to semesters a study was conducted in the Mechanical Engineering Department to determine what other universities were doing in the area of senior design. The initial study was conducted in late 1998 and included a total of 21 mechanical engineering programs, most of which operated using the semester system. Two of the universities included in the study were on the quarter system, Georgia Institute of Technology and California Polytechnic State University. One of these, Georgia Tech was in the process of converting to semesters with the change to take place effective in the fall of 1999. This study indicated that majority of the schools required that students complete a one semester senior design project course which in most cases was designated to be worth a total of three credits. Three of the eight universities designated as "Benchmark Institutions" by Michigan Tech however required a two-semester senior design project experience. A decision was subsequently made that the mechanical engineering program at Michigan Tech would plan on requiring a two semester senior design experience as a graduation requirement for all ME students. This decision was made based both on consideration of $\mathrm{ABET}$ requirements and the interest in moving towards providing more meaningful industrially sponsored design projects.

The study of other mechanical engineering programs was recently updated by rechecking the web sites of several of the universities previously examined, as well as checking the design requirements at three additional universities. These include the University of Cincinnati, Brigham Young University, both of which were identified as having a significant emphasis on design ranging from concept to prototype construction and evaluation. The third university added to the list was Worcester Polytechnic University. The point of this renewed interest in examining what other universities are doing in the area of mechanical engineering design was to become aware of how Michigan Tech is doing in providing a relevant experience in mechanical 
engineering design as compared with other programs across the country. The net result of this examination is that our program ranks at the high end in terms of design requirements with a full year of design and emphasis on taking design projects from concept development to prototype construction, testing and evaluation.

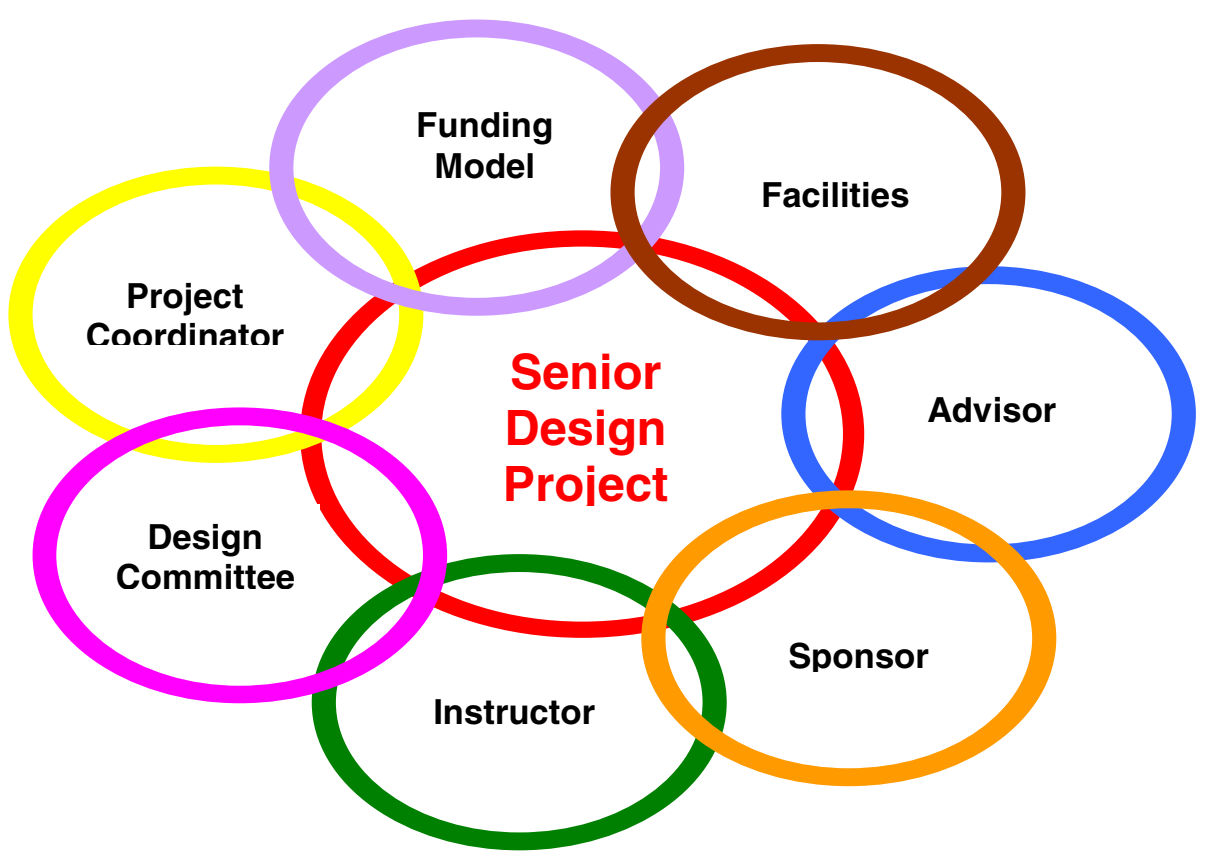

Figure 1: Integration of Project Organization/Components

Project Organization and Delivery Structure

\section{Courses and Projects}

The first course, MEEM4900 Senior Design I, is directed toward developing an engineering proposal to meet a Sponsor's design objectives. This course features two hours of faculty-led discussion and lectures per week on design methodology, teaming, design principles, information sources, patents, product liability, ethics, etc. The equivalent of a three-hour project lab is allocated to Project Teams and their Advisors. The second course, MEEM4910 Senior Design II, is directed toward the completion, physical realization, and optimization of the design. This course focuses on the Team Project and the Advisor. One hour per week is reserved for faculty-led discussion of optimization, failure mode and effects analysis, coordination of presentations, and for curricular assessment activities where access to the entire class is needed. The equivalent of a nine-hour project lab is allocated to Project Teams and Advisors. The integration of each component is illustrated in Figure 1 and described below.

\section{Sponsorship}

Funding for the projects comes from three sources: Corporate sponsorships, University/Department sponsorships and student laboratory fees. Corporate sponsorship of Senior Design projects is crucial to the success of the program: it provides real projects, with realistic expectations and funding. Teams on Corporate sponsorships 
quickly learn that professionalism takes precedence over grades, and that meeting the needs of the Sponsor has a high priority. Since corporate Sponsorships typically require some measure of confidentiality, it is necessary to provide alternative projects. The University/Department sponsorships carry no confidentiality requirements and are directed toward development of designs supporting the University's teaching and research activities, e.g.: student design competitions, design of laboratory apparatus, design of research equipment, etc. The student laboratory fees help to support the general costs of maintaining the design studios, labs and prototyping shops.

\section{Funding Model}

The funding model for Senior Design was developed to approach a "steady state" after three years. During the first year, the department initial expenses were for facility renovation and computer workstations and partial underwriting of Team expenses, with corporate sponsorship of eleven projects. After the third year, the number of corporate sponsorships has stabilized at approximately thirty and total funding fully covers infrastructure and Team expenses. Infrastructure expenses include a full-time Senior Design Coordinator, a full-time machinist, part-time office support staff, and maintenance of workstations in the Student Design Center. Team expenses include Project labor/materials, Team/Advisor travel, and Student Design Center expendables. Over fifty percent of the total funding covers direct Team expenses.

\section{Project Coordinators Role}

The Senior Design Project Coordinator is the liaison between the Sponsor, the Team and the University. Without the Sponsor, the program could not succeed: the University could not afford the expense of these projects and the design Teams would lose the impetus for design realization. On the other hand, the Sponsor benefits from the generation of fresh ideas and new approaches with minimum expenditure of its own resources.

The Coordinator works to ensure that the University's resources are managed in a fashion that makes it advantageous for Sponsors to provide projects outside their organizations in the face of the additional risks associated with confidentiality and intellectual property. The Coordinator's duties also include project and budget tracking, legal paperwork, maintenance of facilities and resources, and coordination with the Department's Design Committee. Although the Coordinator may participate in assisting the Teams with problem resolution and brainstorming, the Coordinator's main priority is to forestall changes of project scope after the project has been initiated.

\section{Project Selection}

Project selection depends on the needs of the Sponsor and the priorities of that business. But the Project must also meet the pedagogical needs of the Senior design students. The Project Coordinator must have sufficient plant and project experience to be sensitive to both sets of needs. In order to remain compatible with the capabilities of the available Advisors, Projects must have significant content in one or more of the following areas: dynamic systems, solid mechanics, manufacturing, and energy/thermo-fluids; and should require approximately 200-400 hours of professional engineering time. Key Sponsor 
considerations are Sponsor resources, past experience with Sponsor, availability and quality of Sponsor's contact people, potential impact on Sponsor's business, the potential for follow-on Projects, Intellectual Property, and Confidentiality. Key Department considerations are Department resources, fabrication requirements, Advisor availability, engineering content, and funding requirements. The Project Coordinator looks for, and tries to formulate, Projects for which alternative solutions have already been identified, in order to shorten the time typically required for ideation. For the same reason, Projects requiring extensive preliminary study to establish root causes are avoided.

\section{Project Distribution}

Problem statements and objectives of all sponsored and un-sponsored projects are presented during the first class meeting. Handouts and web postings are not provided, because of the proprietary nature of the sponsored projects. Instead, project descriptions are posted at the Student Design Center and each student is given one day to review the descriptions and prepare bids for his/her top three project preferences. Each bid must contain a statement justifying the student's preference, a summary of the student's pertinent qualifications and skills, the student's resume, and a statement of willingness to sign an Intellectual Property Agreement. The Design Committee reviews all bids and makes Team assignments based on the information provided in the bids. Although priority is given to forming viable teams for each project, an attempt is made to satisfy each student's highest preferences while rewarding well-presented bids. Over ninety percent of the students are matched with one of their top three project preferences. Students unwilling to sign an Intellectual Property Agreement are assigned to Projects that do not require such an agreement. The Design Committee also designates a Temporary Spokesperson for each Team, on the basis of qualifications and project preference.

Team assignments are distributed during the second class meeting. The Team members are immediately relocated to sit together for the balance of the meeting. Each Temporary Spokesperson then works with the Team members to set the first Team meeting time and place, exchange e-mail and telephone information, set the first Meeting with the Team Advisor, select the Team Spokesman, and communicate this information to the Instructor. In this meeting only, changes in Team makeup may be done through swapping, subject to approval by the Design Committee.

\section{Advisor's Role}

An Advisor is assigned to each Project on the basis of professional background and desire to interact with the Project's Sponsor. The Advisor's role is to guide the Team through the design process, offer advice when appropriate, steer the Team when warranted, and help the Team to find information when necessary. The Advisor interacts with the Team through at least one weekly, hour-long meeting, and often travels with the Team to the Sponsor's facility or participates in Team videoconferences with the Sponsor. It is not intended that the Advisor be the Team's primary source of technical information; the Advisor is briefed to encourage the Team to generate and explore its own concepts, while admonishing the Team to follow a rational approach. 
Twice per semester, the Advisor grades the Team's overall performance, and then develops individual grades which average around the Team grade. The Advisor may choose to ask each student to fill out self-evaluation or teammate evaluation forms, and may study each student's Design Journal/Portfolio and Weekly Activity Reports to supplement the first-hand information gained from the weekly meetings. The Advisor also participates in the Design Committee's evaluation of the Team's Oral Presentations and Poster Presentations, and shares responsibility with the Instructor in the evaluation of the Team's Written Report.

Twice per semester, the students provide anonymous feedback to the Advisor in the form of a short evaluation of the Advisor's availability, interest, communication, and other issues, using a form provided by the Instructor.

\section{Instructor's Role}

Working through the Design Committee and the Advisors, the Instructor is responsible for guiding the Senior Design course to ensure that its outcomes meet academic requirements, while meeting the objectives of the Sponsors. The Instructor's duties include the presentation of lectures and coordination of the course activities, e.g.: Poster Presentations, Oral Presentations, and Written Reports.

The Instructor participates in the Design Committee's evaluation of the Team's Oral Presentations and Poster Presentations, and works with the Advisors in the evaluation of the Written Reports. The Instructor is also responsible for compiling all grading information and establishing the final grades for the course.

\section{Design Committee's Role}

A Design Committee guides the conduct of the course. In addition to providing course oversight and continuing assessment, this Committee resolves academic and logistic issues. The Design Committee is comprised of the current Course Instructors, the Director of Undergraduate Studies, the Project Coordinator, the Teaching Assistants, and interested members of the design faculty who have either been, or will eventually become, course Instructors. This makeup fosters continuity in course content and conduct, and provides each new Instructor with the opportunity to introduce, discuss and implement new ideas in a climate of consensus. The Design Committee conducts the evaluation of the Team's Oral Presentations and Poster Presentations, and shares the responsibility for course Assessment. In cooperation with the Department's Curriculum Committee, the Design Committee uses this course's access to eighty percent of the Department's graduating seniors to expedite the Department's curricular assessment activities.

\section{Facilities}

The ME-EM Department had developed facilities and resources for the use of senior design students. The Design program is supported by: a) the Cuskie Design and Creativity Center, which features 23 design studios with high-end CAD workstations, and a Resource Library; b) the Center for Product Realization, which features complete metal and non-metal shop facilities; 
c) three Conference and Meeting spaces, complete with networking, video-conferencing and teleconferencing capabilities; and d) a 3D printer. Funds are also used to acquire commonlyused laboratory equipment and, when the occasion warrants it, research support equipment can be borrowed for use on Team projects.

Evaluation and Assessment

Continuing assessment of the design sequence has led to many changes in the course format and content, and in the roles of the Sponsor and Advisor. As Students, project Sponsors, faculty Advisors and Industrial Advisory Committee members review the project and learning outcomes, the Senior Design Committee evaluates and makes recommendations to the full faculty for change(s).

- Design Committee Evaluation of Oral Presentations and Poster Presentations

- Industrial Advisory Committee Evaluation of Oral Presentations and Poster Presentations, using guidelines provided by the Design Committee

- Discussions with a student advisory board made up of eight to ten randomly selected senior design students

- Input from Industrial Advisory Committee members who have Sponsored Design Projects

- Sponsor Evaluation of project work, using guidelines provided by the Design Committee

- Joint Advisor/Instructor evaluation of Written Reports

- Taped Interviews of a sampling of graduating Seniors regarding the conduct of the Senior Design Course

- Senior Exit Interviews, providing feedback from $100 \%$ of graduating Seniors regarding their confidence in meeting each ABET Outcome

- Fundamental Concepts Examination, administered to $100 \%$ of graduating Seniors to assess overall capabilities for meeting several ABET Outcomes

The information gathered from all of the sources listed is discussed at length during weekly meetings of the Senior Design Committee. This helps to keep everyone involved aware of issues and concerns of both the students and others involved with the course. In addition the Design Committee has been working with representatives from other departments across campus to help facilitate offering more truly interdisciplinary design projects for senior design students primarily but not exclusively in Biomedical, Electrical, Material-Metallurgy and Mechanical Engineering.

Another ongoing effort in assessment centers around providing feedback to the faculty advisors concerning the students' perceptions of how they are doing in facilitating the students design work during the year. A special evaluation form was developed for this purpose. The form is entitled the "MTU Senior Design Project Advisor Rating Instrument" and consists of the following ten questions as well as two specific "open ended questions":

1. The senior project advisor assisted us in establishing goals and objectives early in the semester.

Proceedings of the 2003 American Society for Engineering Education Annual Conference \& Exposition Copyright @ 2003, American Society for Engineering Education 
2. Throughout the semester, the senior project advisor provided the technical advice we needed to fully develop our project.

3. The senior project advisor met with us at least once every two weeks during the semester.

4. The senior project advisor was generally available during posted office hours.

5. The senior project advisor consistently encouraged us to set and meet deadlines and to prepare presentations, posters and papers.

6. The senior project advisor made effective use of group meeting times.

7. The senior project advisor gave us timely feedback on our performance.

8. The senior project advisor seemed knowledgeable about course policies and procedures.

9. The senior project advisor helped us to secure equipment and facilities when necessary.

10. Taking all things into consideration, I would say that the senior project advisor served as a valuable resource in our senior design experience.

The "open ended questions" on the backside of the form are listed below.

1. What one thing could your advisor have done to make the senior design project experience more valuable to you?

2. What one thing do you wish your senior project advisor would change to improve your experience in the senior project program?

An additional space for other comments and suggestions is also provided. The intent of using this form is to help advisors to improve as needed, based on input from the senior design students. The form was developed as a first cut at providing feedback of a meaningful nature. The standard teaching evaluation forms currently available were judged to be woefully ill suited for this task.

\section{Benefits}

Senior Design Day

After one complete academic cycle of the new format the department wanted to place a large effort on project fruition. The students, faculty advisors, sponsors, industry advisors, faculty, staff and other students of the university are invited to view and evaluate the projects during a day-long event at the university. In addition local high schools are invited to learn more about Mechanical Engineering. Mechanical engineering senior classes are cancelled for the day so the students can focus on the event and the importance of presenting project results. The formal presentations are videotaped and assessed with the entire day culminating in a senior banquet and other awards for the students involved. This event will continue to grow and become an important component in the education of the mechanical engineer at MTU.

Projects Evolving into Research Opportunities The projects afford an excellent opportunity for Advisors and Sponsors to better understand needs and capabilities. The 
project funding affords the Advisors with opportunities to visit the Sponsor facility, and for the Sponsor to interact with a professional in the subject of interest.

\section{Patents}

Students in the senior design sequence are required to emphasize the development of innovative design solutions to their design problems. Those teams whose solutions show economic potential have been encouraged to pursue patents to protect their intellectual property. The University's Intellectual Properties/Trademarks office works with the students and helps to evaluate their ideas. There are currently six ideas from senior mechanical engineering design teams under consideration for patent applications. Several of these show potential but may need additional development before moving forward. The University covers all costs associated with the patent applications and the students involved are eligible for the same rewards as the University's employees.

\section{Alumni Relations}

Projects have been acquired from former students of the Design course, some within one year of graduation. A good design experience helps foster good alumni relations. The projects also give older alumni chances to renew relationships with their alma mater. Posters and mockups from senior design projects also make excellent displays and conversation pieces in the recruiting of potential students.

\section{Future Directions}

\section{Selection of Design Projects}

The current timetable favors the Project whose Objectives focus on identifying needs and meeting performance specifications, as opposed to the Project which focuses on troubleshooting and problem solving. For example, a Project which requires the Team to discover the source of a (vibration) problem before embarking on a design fix cannot be conducted on the same timetable as a Project which begins with a description of that source. The Design Committee has learned that the former type may require too much background study, leaving too little time to address the other objectives of the course within the time available, and encourages Projects of the latter type. The Design Committee is still discussing means to accommodate both types of problem.

\section{Multi-disciplinary projects}

The Design Committee has conducted discussions with the Electrical, Materials Science and Chemistry Departments, attempting to identify differences and similarities in delivery of the Design experience, and to explore ways to expedite multidisciplinary Design projects. Each student in a multi-disciplinary Team must realize the ABET outcomes specified for his/her parent Department, regardless of that Team's makeup. The major difficulty lies in the ways each Department's curriculum is organized to meet its perceived ABET Objectives. In some curricula, the students are exposed to a prerequisite course in Engineering Practice prior to the Design course; others imbed these Objectives into the required design milestones. Resolving this may require unification of the structure of the Capstone design experience across a college's engineering departments. A greater difficulty lies in the expectations of the design project itself: 
some curricula focus on development of concept, as in a plant design, without requiring physical realization of that design; other curricula require physical realization and evidence of optimization testing. This poses significant problems when soliciting for support of multidisciplinary projects, since each project must meet the Educational Objectives of every student's curriculum.

\section{Intellectual Property}

After dealing with some significantly challenging issues regarding intellectual property concerns of both the university and individual companies, a procedure had been established to help enable students to participate in sponsored projects and to pursue patents to protect their intellectual property. As with any issue that has monetary considerations it is expected that there will be future discussions between the design project coordinator, University Administrators and representatives from industry. The goal is to safeguard the proprietary information from individual companies while satisfying the concerns regarding the development of creative solutions to industrial problems by students on campus. The senior design students benefit tremendously from being involved in real industrial projects that meet the course requirements in terms of providing a sufficient level of challenge. They are also made aware of real issues regarding intellectual property and assignment of creative developments to employers during the process of involvement with the projects. At the minimum a proprietary rights document usually must be signed by students prior to their being approved to work on sponsored projects. Other intellectual property concerns must be addressed on an individual basis with the sponsoring companies.

\section{Conclusions}

The Department of Mechanical Engineering-Engineering Mechanics at Michigan Technological University has developed a two-semester senior design project course sequence that emphasizes real industrially sponsored projects. A considerable effort was put into designing the course structure and developing resources to enable students to successfully complete challenging design projects from concept to actual prototype construction and testing. A continual assessment process is being used to guide the development of the course sequence. This process involves obtaining feedback from students, faculty advisors, technical staff members, industrial sponsors and members of the Department's Industrial Advisory Committee. Results to date indicate that the two-semester design sequence is providing students with a very valuable and much needed introduction to engineering design at a high level of professionalism. The Department will continue to work at improving all aspects of the design project course sequence. This is necessary to meet the educational needs of the large number of students in an efficient and effective manner.

\section{HAROLD A. EVENSEN}

Harold Evensen is the Associate Chair and Director of Undergraduate Studies for the Department of Mechanical Engineering-Engineering Mechanics at Michigan Technological University. He received a B.S. in Mechanical Engineering from Michigan Tech in 1961, and the M.S. and PhD. Degrees in Mechanical-Aerospace Engineering from Syracuse University in 1964 and 1966 respectively. Before returning to Michigan Tech in 1970, he served 
with N.A.S.A-Ames Research Center and Whittaker R\&D-San Diego, working in composite materials, noise control and vibration control.

\section{PAULA F. ZENNER}

Paula Feira Zenner is the Director of Operations and Finance for the Department of Mechanical EngineeringEngineering Mechanics at Michigan Technological University. She received a B.S. degree in Mechanical Engineering from Michigan Tech in 1987 and an M.S. degree in Operations Management from Michigan Tech in 1993. Before returning to graduate school she spent four years as a Technical Specialist in the computer industry.

\section{THOMAS R. GRIMM}

Thomas R. Grimm is Associate Professor of Mechanical Engineering in the ME-EM Department at Michigan Technological University and is course coordinator for the mechanical engineering senior design project courses. He received a B.S. Degree in Electrical Engineering from Marquette University, an M.S. in Mechanical and Aerospace Science from the University of Rochester and the Ph.D. in Engineering Mechanics from Michigan Technological University. Prior to joining the faculty at MTU Tom was an Assistant Professor of Mechanical Engineering at the University of Tulsa and worked for about four years in industry.

\section{MARTIN D. TERVO}

Martin Tervo is the Senior Design Project Coordinator for the Department of Mechanical Engineering-Engineering Mechanics at Michigan Technological University. Martin received a B.S. degree in Mechanical Engineering from Michigan Tech in 1990. After graduation he was employed for 9 years by DaimlerChrysler Corporation were he has received a number of patents and awards for component design. In 1999 he was employed by Jeffers High School in Painsdale Michigan to teach the Technology and Industrial Arts program. 